\title{
"That Makes Sense Now!": Bicultural Middle School Students' Learning in a Culturally Relevant Science Classroom
}

\author{
Deoksoon Kim \\ So Lim Kim \\ Mike Barnett \\ Boston College \\ U. S. A.
}

This study describes how culturally relevant pedagogy in a project-based science class improved student engagement and comprehension. We focus on bicultural students exploring cultural objects and household inventions with family members and connecting scientific concepts to their families' funds of knowledge. We use a multiple-case study design to explore six middle school bicultural students' experiences with culturally relevant activities. Findings describe bidirectional knowledge transfer between the home and the classroom in a way that engaged students, affirmed their home cultures, and facilitated subject matter learning.

Keywords: Culturally relevant science, bicultural students, invention-based learning (IBL), culturally responsive teaching

\author{
Literature Review \\ Methods \\ Findings \\ Discussion/Conclusion \\ References \\ Author Contact
}

Immigrants and children of immigrants are a rapidly growing population in the United States (National Center for Education Statistics, 2016). As the number of first and second-generation immigrants rises, more bicultural students are enrolled in American schools (Saad et al., 2012; West \& Maffini, 2019). Unlike bilinguals, biculturals may not be fluent in their heritage language but are often deeply embedded in both heritage and dominant cultures. Biculturals are defined as individuals who navigate between their family culture and the dominant culture (Benet-Martínez \& Haritatos, 2005; Schwartz \& Zamboanga, 2008; West \& Maffini, 2019), even if they were born and raised in the United States.

Science education has had too "little recognition of the linguistic and cultural resources that non-mainstream individuals and groups bring to the science classroom" (Lee, 2005, p.491). Despite the increasing number of bicultural 
students, many science teachers still struggle to address their cultural heterogeneity (West \& Maffini, 2019). Unsatisfactory performance in science, technology, engineering, and mathematics (STEM) creates an urgent need for implementing engaging and accessible science curricula for all students, including biculturals (Business Roundtable Group, 2005; National Center for Education Statistics, 2005). In this study we describe an innovative way in which culturally relevant pedagogy (Ladson-Billings, 1995) can be applied in science classes to help student engagement and comprehension.

To better engage and support diverse student populations in science classes, we implemented an invention-based learning (IBL) approach to middle school science (Kim et al., 2019; Kim \& Kim, 2021). IBL is a type of project-based learning implemented through a collaboration among Boston College, the Lemelson-MIT Program, and a local school district. It cultivates culturally relevant science learning environments by connecting students' home cultures to an invention challenge (Kim et al., 2019).

We modified one of the eight Lemelson-MIT IBL curricula, called "Chill-out," and added what we call a "HomeFun activity" to the unit, in order to facilitate culturally relevant pedagogy. This unit focuses on heat transfer and guides students to invent lunch boxes which block heat transfer and keep liquid cold. The HomeFun activity connects students' home knowledge to the project. Students explore cultural objects such as traditional cooking devices and household inventions with family members, in order to discover scientific concepts embedded in cultural objects and practices. The HomeFun activity is aligned with the curriculum unit and designed to help knowledge transfer from home to school by connecting students' cultural backgrounds with school curriculum. Even though knowledge transfer has been investigated extensively (Barnett \& Ceci, 2002; Bereiter \& Scardamalia, 1987; Chi \& VanLehn, 2012; Engle, 2006; Engle et al., 2012; Perkins \& Salomon, 2012; Scardamalia \& Bereiter, 1987), few studies explore knowledge transfer in a way that involves bringing home culture to school as a way of facilitating learning. This study discusses how the engagement of culture and family in a culturally relevant school activity can promote knowledge transfer.

Research has been done on culturally relevant pedagogy in science, but there are few studies of culturally relevant invention-based learning. Similarly, although English language learners' linguistic and cultural needs have been explored by researchers (Lee, 2005; West \& Maffini, 2019), there is limited research on bicultural students. Taking a sociocultural perspective on science learning (Vygotsky, 1978), this study uses a multiple-case study design to explore six middle school bicultural students' experiences with culturally relevant HomeFun activities in the IBL curriculum. The study addresses the following research questions:

- How do bicultural middle school students draw on cultural knowledge in HomeFun activities? 
- How do bicultural middle school students perceive and experience culturally relevant HomeFun activities as they learn science in the IBL program?

- How do culturally relevant HomeFun activities foster knowledge transfer from home to school?

\section{Literature Review}

In order to answer these questions, we build on previous research in culturally relevant pedagogy, funds of knowledge, and knowledge transfer.

\section{Culturally Relevant Pedagogy (CRP)}

Culturally Relevant Pedagogy (CRP), also referred to as culturally relevant teaching (Ladson-Billings, 1994), was developed in the 1990s as a more appropriate approach with African-American students. CRP engages students' cultural competence and improves academic achievement (Brown et al., 2019; Dallavis, 2014; Ladson-Billings, 1995; Milner, 2017). Ladson-Billings (1994) argues that CRP is not teaching dominant culture using minority students' cultural referents. Instead, it teaches that "they are aspects of the curriculum in their own right" (Ladson-Billings, 1994, p.180). Advocates of CRP have extended early work to create a culturally inclusive approach to teaching marginalized students (Bassey, 2016; Djonko-Moore et al., 2018; Gay, 2002; Ladson-Billings, 2009, 2014; Morrison et al., 2008; Pak, 2018).

\section{Culturally Relevant Pedagogy in Science}

Despite the popularity of CRP, most pedagogy does not incorporate diversity, culture, or language as part of the curriculum (Boutte et al., 2010; Johnson 2011; Kim et al., 2019). Considering science as "facts" leads to a misperception that science should not connect with culture (Boutte et al., 2010; Johnson, 2011; Laughter \& Adams, 2012). Teachers often believe that CRP is appropriate in social studies, language arts, and fine arts, but not in "hard sciences" and mathematics (Boutte et al., 2010, p.2). Many have tried to overcome this misperception through interventions designed to help teachers implement CRP in science classrooms (Adams \& Laughter, 2012; Barton, 2002; Gay, 2002; Kim et al., 2019; Laughter \& Adams, 2012; Mensah, 2013).

Various researchers (Djonko-Moore et al., 2018; Gay, 2002; Lee, 2002; Lee et al., 2005; Milner, 2017) have used CRP to "make up the pedagogical bridges that connect prior knowledge with new knowledge, the known with the unknown, and abstraction with lived realities" (Gay, 2002, p.113). Gay (2002) highlights the importance of knowing relevant cultures and connecting to students' prior knowledge. She argues that culturally relevant learning experiences can make academic learning more meaningful to students. She provides examples of CRP in science which provide culturally congruent classroom learning, build communities, and facilitate cross-cultural communication.

Many studies have shown that students' homes are an important site for learning science and engaging in scientific practices (Brickhouse et al., 2000; Djonko-Moore et al., 2018; Kim et al., 2019; Ochs \& Taylor, 1992; Solomon, 2003; 
Zimmerman, 2012). When educators make a connection between school and home, students acquire science concepts through knowledge and experiences they are familiar with at home (Brickhouse et al., 2000). As Solomon (2003) has observed, families can practice scientific activities "happily and naturally at home" (p. 229). She shows how home-based science learning is "not only rich in supportive emotions, but also imbued with idiosyncratic attitudes toward science education" (p.219). Similarly, a longitudinal study by Zimmerman (2012) shows how students can gain scientific knowledge and practices by engaging with a hobby at home. Her participants' engagement with animals and knowledge about animal behavior contributed to their understanding of scientific practices in biology. Tan's and Barton's (2008) ethnographic study of two Latina students also shows how students' interests and hobbies outside of school can become a learning tool. Their participants used definitions of biological terminology to write lyrics to a pop song. The song became popular among classmates, and students used the song while learning subject matter. It subsequently became a community resource for all students.

\section{Funds of Knowledge}

Moll, González, and subsequent researchers have used the term "funds of knowledge" to refer to cultural knowledge from students' home environments that can be connected to classroom lessons (Barton \& Tan, 2009; González et al., 2006; McLaughlin \& Barton, 2013; Razfar \& Nasir, 2019; Upadhyay, 2009; Warren $\&$ Rosebery, 2008). Funds of knowledge are the historical and practical knowledge accumulated across generations among cultural groups (Moll et al., 1992).

Basu and Barton (2007) examine the relationship between funds of knowledge and science learning. Their findings indicate that students' interests increase when the learning environment matches their desired social relationships as well as "their views on the purpose of science" (Basu \& Barton, 2007, p.466). Students who develop an interest in science are more likely to explore scientific phenomena outside of school and investigate at a deeper level. Similarly, many researchers find that students in funds of knowledge science projects participate more, perform significantly better, and make positive connections between themselves and science (Barton \& Tan, 2009; Maulucci et al., 2014).

\section{Knowledge Transfer}

In order to apply students' funds of knowledge successfully, it is important to know how knowledge transfers from one context to the other. Knowledge transfer involves mastery of content such that students are able to apply it in a different setting (Barnett \& Ceci, 2002; Engle, 2006; Kim \& Kim, 2021; Salomon \& Perkins, 1989; Scardamalia \& Bereiter, 1987). A central goal of education is for students to apply what they learn in school to the outside world (Kim \& Kim, 2021; Perkins \& Salomon, 2012). Unfortunately, many studies demonstrate that current education often does not foster knowledge transfer (Chi \& VanLehn, 2012; Engle et al., 2012). Because school knowledge is generally decontextualized, "people commonly fail to marshal what they know effectively in situations outside the classroom or in other classes in different disciplines" (Engle et al., 2012, p. 248). 
Culturally relevant pedagogy can help with this problem because it connects subject matter to home knowledge in a way that can facilitate bridges between inschool and out-of-school learning.

\section{Methods}

We used a multiple-case study design to investigate bicultural students' experiences in the invention-based learning program (Merriam \& Tisdell, 2015). This method allowed us to focus on details of each bicultural student's experience while comparing across cases.

\section{Context}

This project is part of a collaboration among Boston College, the LemelsonMIT (LMIT) Program at the Massachusetts Institute of Technology, and a public school district in the Northeastern United States. We modified one of the LMIT Junior Varsity "InvenTeams" activity guides called "Chill-out." The "Chill-out" curriculum was originally created as an after-school activity guide. Together with participating teachers, we implemented a modified version of the "Chill-out" curriculum in 7th grade science classes as part of a heat transfer unit. Because this is a multi-institution project, we independently obtained IRB approval from two universities: Massachusetts Institute of Technology (MIT) and Boston College.

\section{Chill-out Curriculum}

The "Chill-out" curriculum focuses on heat transfer concepts such as thermal equilibrium, conduction, convection, and radiation. It provides students opportunities to use knowledge of heat transfer to invent objects for daily life. Students gain STEM knowledge of heat transfer concepts through diverse class activities and lab experiments. After learning the concepts, students apply these concepts to create a lunchbox that prevents heat transfer. After completion, students and teachers test the lunch boxes for effectiveness. The experimental results and design of the lunch box invention are recorded in a patent application (Figure 1).

Figure 1 shows two students' design for their lunch box. They both used bubble wrap and aluminum foil as important components. 


\section{Figure 1}

Samples of Students' Lunch Box Invention Designs and Experimental Results

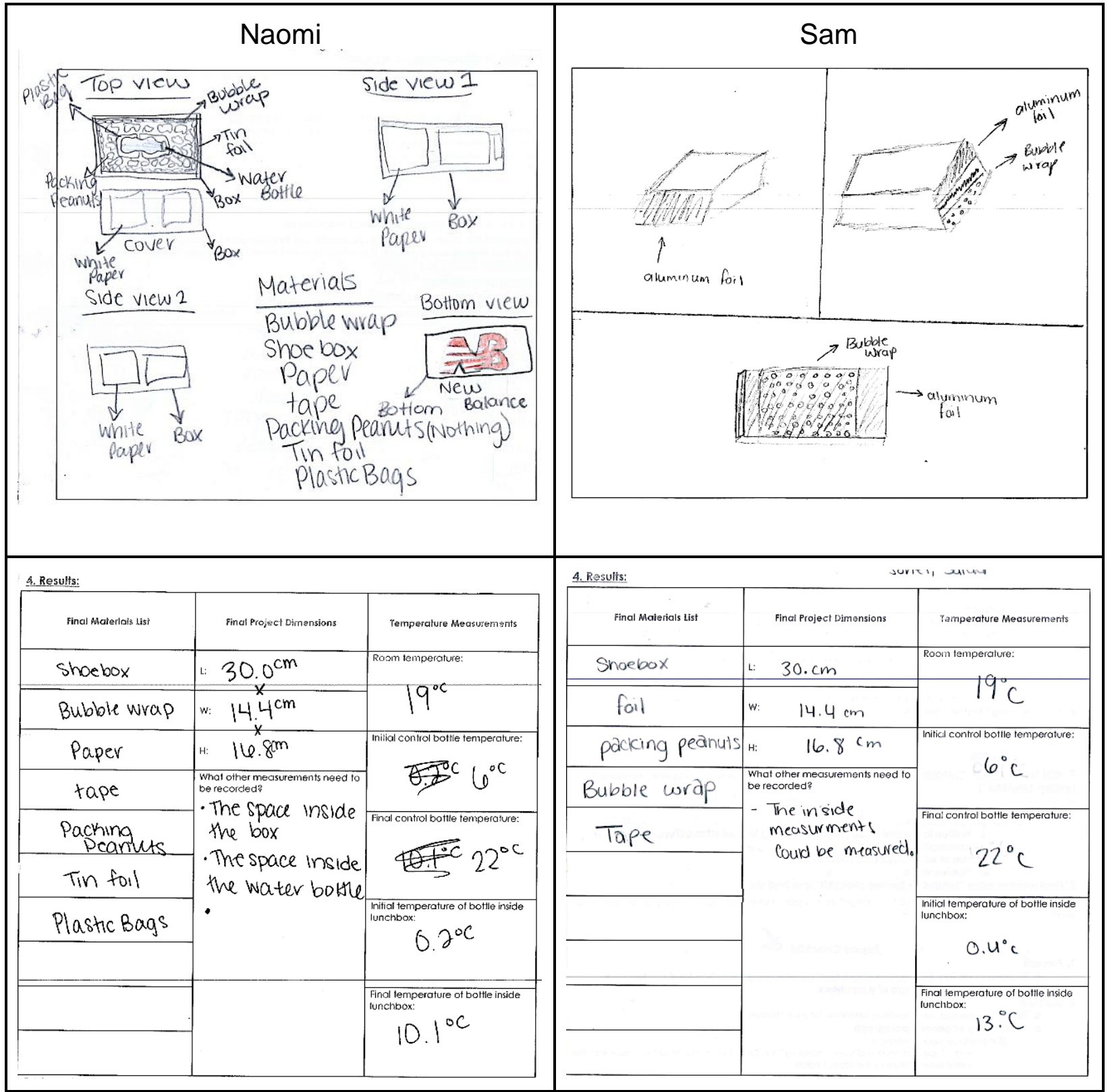

We modified this curriculum to make it more accessible to English language learners by adding visualizations, science literacy tasks (the patent writing application), and HomeFun activities. In this paper, we focus our analysis on the HomeFun activities. We provided workshops and conducted meetings with the teachers before curriculum implementation. We focus on Mr. Kyle's classroom for this study. He was a skilled 7th grade science teacher with five years' experience. We chose Mr. Kyle's classroom because he had students from diverse cultural backgrounds. 


\section{HomeFun Activities}

Four HomeFun activities were provided during the "Chill-out" curriculum for students to complete with their families (see Table 1). The HomeFun activities asked students to work with family members to uncover funds of knowledge relevant to the invention project. These activities promoted culturally relevant learning both at home and in school (see Figure 2). Mr. Kyle shared students' and his own HomeFun activities in class, to bring relevant knowledge from the diverse home cultures into his classroom.

\section{Table 1}

The List of HomeFun Activities

1. How we heat or cook things in my home country/town

2. Famous inventions from my home country/town

3. Clothing that keeps us warm or cool

4. How we keep cool in my home country

Figure 2 presents two examples of HomeFun activities, "How we heat or cook things in my home country/town" and "Famous inventions from my home country/town." 
Figure 2

Samples of HomeFun Activities

How we heat or cook things in my home country/town

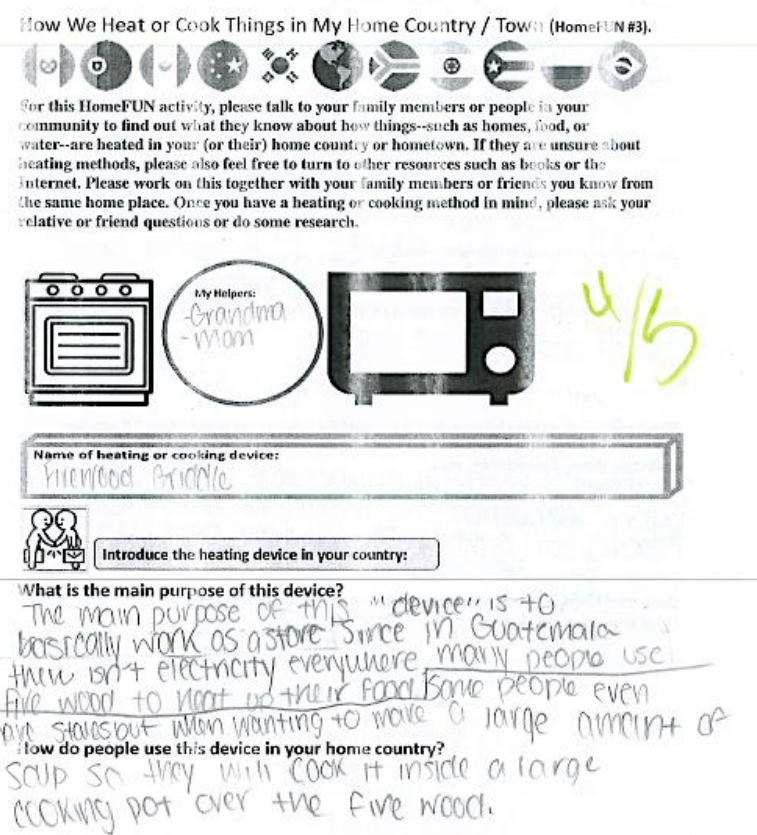

Famous inventions from my home country/ town or elsewhere

Famous Inventions from My Home Country/Town or Elsewhere (HomeFUN \#4)

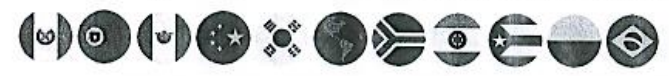

For this HomeFUN activity, please talk to your family members or people in your community , to find out what they know about an invention from your home country/countries (or elsewhere if you prefer). You can discuss any invention that you and your family members are interested in. If they are unsure about a home country invention, please also feel free to turn to other resources such as books or the Internet. Please work on this together with your family menters or friends you know who come from the same place.

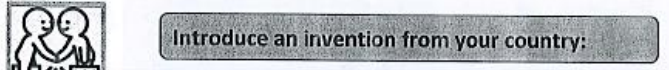

What is your country's invention? Please provide the name and a short description of the invention. If possible, provide a drawing or picture of the invention. My Countrys invention is the first

battery. This battery can make things work.

Why did you and your family choose this invention? we chose the battery beculuse we use batteries everyday and we are from ltaly so we thought if would be coolds it caught our attention. What makes your country's invention unique and useful? The baltery is useful because batterys make many things work. peaple use batteries everyday.

Sketch the invention below

\section{Participants}

We selected six bicultural students from Mr. Kyle's classroom using purposive sampling (Merriam \& Tisdell, 2015). We used three selection criteria in choosing participants: 1) participants self-identified as bicultural, 2) they were immigrants or children/grandchildren of immigrants, and 3) they had to fully participate in and complete the project. 
Table 2

Student Demographics

\begin{tabular}{ccccccc}
\hline & Mandy & Naomi & Cynthia & Nidia & Mia & Sam \\
\hline Grade & 7 th & 7th & 7th & 7th & 7 th & 7th \\
\hline Gender & Female & Female & Female & Female & Female & Female \\
\hline $\begin{array}{c}\text { Home } \\
\text { Country }\end{array}$ & Italy & Canada & Greece & Italy & Guatemala & Morocco \\
\hline
\end{tabular}

\section{Data Collection}

We collected four types of data for this study: 1) classroom observation notes, 2) interviews, 3) HomeFun activities, and 4) patent writing application drafts.

1) Observation notes: The researchers observed classroom lessons 3-4 times per week. The lessons included HomeFun activities and subsequent discussions among teacher and students. The researchers' notes were analyzed.

2) Interviews: Research team members conducted two semi-structured interviews with students. The initial interviews, conducted shortly after program completion, took approximately 15 minutes. The follow-up interviews were conducted at the beginning of the following semester and took 30 to 40 minutes. The interview questions included: "What was your experience with the Homefun activities?", "How did you feel doing Homefun activities?", "What HomeFun activity did you like the most?", and "What did you learn from the Homefun activities?"

3) HomeFun activities: We collected the six students' HomeFun assignments. These included the teacher's feedback and comments.

4) Writing drafts: We collected three sets of patent writing application drafts. The first and second drafts included teacher feedback and student revisions and modifications.

\section{Data Analysis}

We analyzed the data inductively. All interviews were transcribed verbatim. We combined the observation notes, interview transcripts, and HomeFun activity data into one data set. Then we used initial codes from the pilot study and conducted open coding as we reviewed the data set. We used ATLAS.ti software. We established 133 initial codes through the process of open coding. The initial codes included, for example, "HomeFun family involvement" and "connection between HomeFun activities and school science." Second, we merged related codes to create categories. For example, "family member's cultural experience" 
and "participant's cultural experience" were merged into the category "cultural experience." When emerging patterns appeared, we reviewed and re-coded the data. Key categories included: cultural engagement, positive invention experiences, relationship between culture and science, family involvement and engagement, attitudes towards HomeFun activities, and helpful support/resources/strategies. All researchers reviewed the categories multiple times before finalizing them. After confirming the validity of each category and triangulating across data, we developed themes.

\section{Findings}

We organize the findings into three sections: 1) bicultural students' cultural engagement with HomeFun activities, 2) bicultural students' perceptions of and experiences with HomeFun activities, and 3) connections between the HomeFun activity and science learning.

\section{Bicultural Students' Cultural Engagement with HomeFun Activities}

Family members contributed cultural examples, experiences, and knowledge to the HomeFun activities for all six bicultural students. Two types of cultural knowledge and engagement appeared in the HomeFun activities: direct and indirect (Table 3). Direct cultural knowledge was cultural understanding acquired through direct experience. Indirect cultural knowledge was gained through family members' experiences.

\section{Table 3}

Family Involvement, Topics for HomeFun Activities, and Types of Engagement with Cultural Experiences

\begin{tabular}{|c|c|c|c|c|c|c|}
\hline & Mandy & Naomi & Cynthia & Nidia & Mia & Sam \\
\hline $\begin{array}{l}\text { Family } \\
\text { Involvement }\end{array}$ & $\begin{array}{l}\text { Father } \\
\text { and } \\
\text { Grand- } \\
\text { mother }\end{array}$ & Mother & $\begin{array}{l}\text { Mother } \\
\text { and } \\
\text { Father }\end{array}$ & Father & $\begin{array}{l}\text { Mother, } \\
\text { Father, and } \\
\text { Grandmother }\end{array}$ & $\begin{array}{l}\text { Mother and } \\
\text { Father }\end{array}$ \\
\hline \multirow[t]{2}{*}{ Topics } & $\begin{array}{l}\text { Brick } \\
\text { Oven }\end{array}$ & Parka & $\begin{array}{l}\text { Greek } \\
\text { Slippers }\end{array}$ & $\begin{array}{l}\text { Italian } \\
\text { Skirts }\end{array}$ & $\begin{array}{l}\text { Guatemalan } \\
\text { Sweatshirt }\end{array}$ & $\begin{array}{l}\text { Moroccan } \\
\text { Clay Oven }\end{array}$ \\
\hline & & & $\begin{array}{l}\text { Wood } \\
\text { Stove }\end{array}$ & Battery & $\begin{array}{l}\text { Firewood } \\
\text { Griddle }\end{array}$ & \\
\hline $\begin{array}{l}\text { Types of } \\
\text { engagement }\end{array}$ & Direct & Indirect & Direct & Direct & Direct & Direct \\
\hline
\end{tabular}

Mia's direct cultural experiences were her main source of information in the HomeFun activities. For example, she explored Guatemalan sweatshirts as insulation that prevented heat transfer, based on her experience with these garments in Guatemala. She indicated that Guatemalan sweatshirts have personal 
meaning because of her experience with family members there. She explored the material and how it absorbs heat and prevents heat transfer.

\section{Picture 1}

Drawing of Mia's Guatemalan Sweatshirts and Firewood Griddle

Clothing that keeps us warm or cool

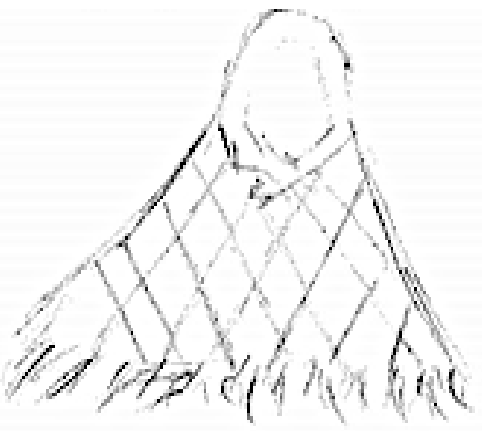

"When I went to Guatemala I bought one for myself. It was really warm."

Science Concept Explained: Insulation
How we heat or cook things in my home country/town

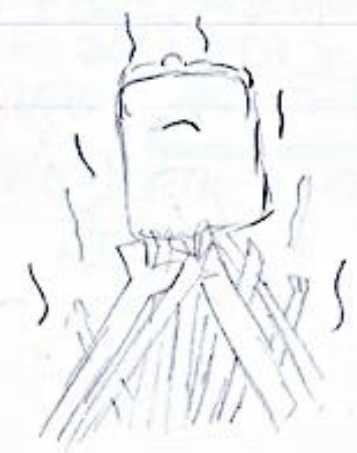

"I chose this heating device because I think it is cool that we don't always need a stove to make food."

Science Concept Explained: Conduction

Mia also described the firewood griddle, a major heating method in Guatemala. She explained that many areas do not have electricity and many people use firewood to heat food. She thought that the firewood griddle was a "cool" way to cook because it is different from what people commonly use in the United States. She referred to her own experience with firewood griddles to illustrate how it heats up food effectively using natural resources (Picture 1). She demonstrated how the oven successfully delivers heat through conduction with firewood directly touching the pot. 


\section{Picture 2}

\section{Drawing of Mandy's Italian Brick Oven and Sam's Moroccan Oven}

How we heat or cook things in my home country/town

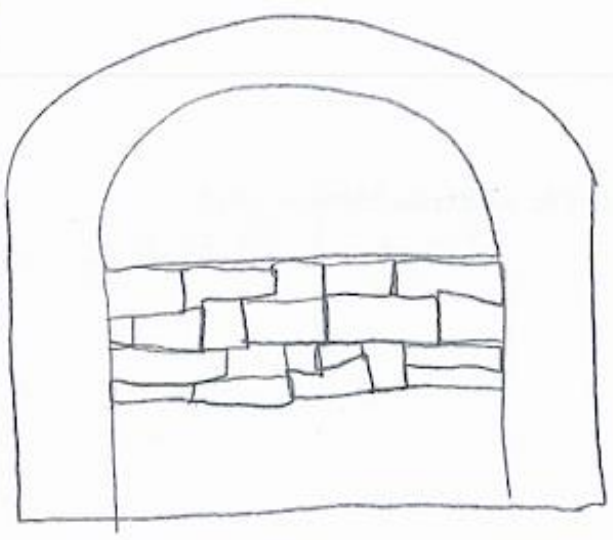

"It gets really hot and the hot air rises to the food. The type of heat transfer...is convection." -Mandy

Science Concept Explained: Convection
How we heat or cook things in my home country/town

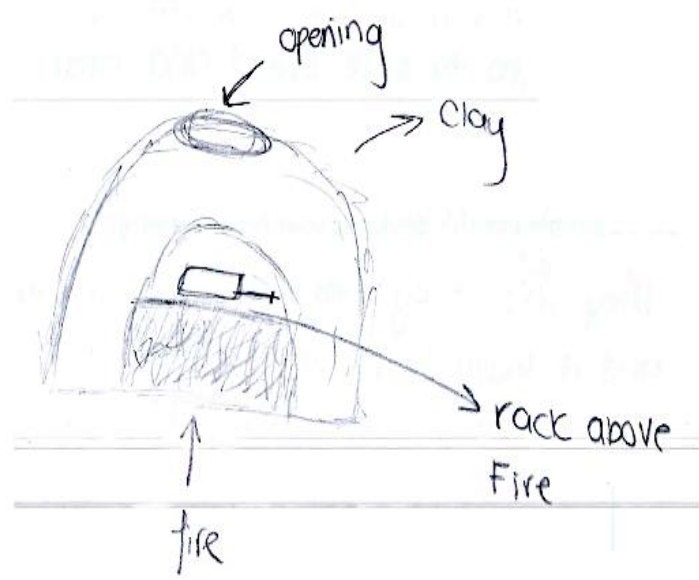

"This heating device has been used for centuries and no home is a home without these ovens. It's a tradition!" - Sam

Science Concept Explained: Convection and Conduction

Mandy and Sam also drew on their own experiences using traditional ovens (Picture 2). Mandy chose an Italian brick oven as a heat transfer device, reflecting on her memories of making Italian food with her grandparents: "At my grandmother's house, we have a brick oven out in the backyard." Mandy showed her knowledge of the oven's energy source and its function: "traditionally, it's used with coal or wood but now usually natural gas or even electricity...it gets really hot and the hot air rises to the food. The type of heat transfer is convection."

Sam also illustrated her knowledge of a traditional oven: "They use it [traditional Moroccan oven] by starting a fire in the clay oven and it usually lasts for 6 hours...this heating device has been used for centuries and no home is a home without these ovens. It's a tradition!" This statement indicated the importance of the oven to Moroccans and her strong connection to customs in Morocco. She described the functions of the Moroccan clay oven (Picture 2) and explained its heat transfer mechanism: "This device uses thermal energy, potential, and radiation... It delivers heat by using conduction and convection. 
Conduction because the fire is below the object. Convection because the air circulating is warmer and helps deliver heat to the object."

Like Sam and Mandy, Cynthia's choice was based on her personal experience with Greek slippers. She introduced traditional Greek slippers, handknitted by her grandmother, as an insulating clothing that prevents heat transfer (Picture 3). "The slippers are fairly easy to make, warm, comfortable, don't take up a lot of space." As background, Cynthia described how Greece has four seasons and the weather gets relatively cold. She also described her own connection: "this (Greek slippers) connects to my family because all the grandmothers make warm slippers that they knit and felt." In another example, she referred to her experience using a Greek wood stove as a cooking and heating device (Picture 3). She indicated her strong connection to Greece, writing how meaningful the device is to her family and how it reminded her of life in Greece.

\section{Picture 3}

\section{Drawing of Cynthia's Greek Slippers and Greek Wood Oven}

Clothing that keeps us warm or cool

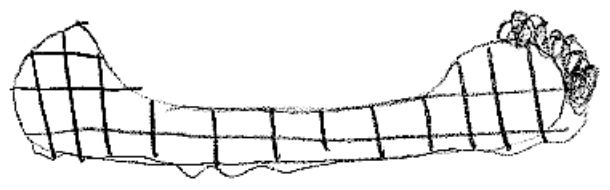

"The color is light and not heavy. Light colors reflect"

Science Concept Explained: Reflection
How we heat or cook things in my home country/town

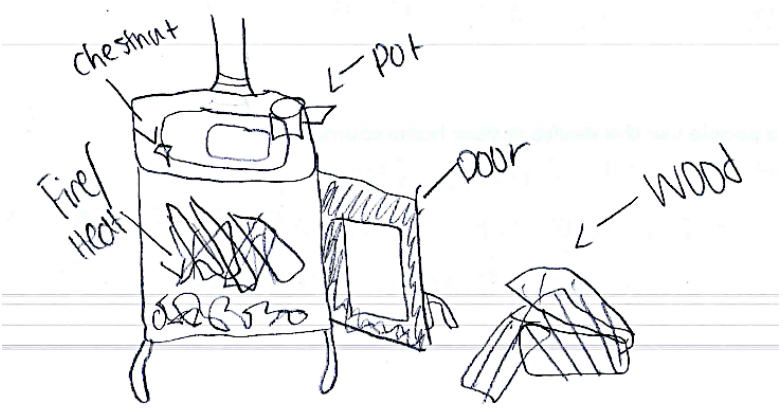

"My grandparents have one (heating device) at their house and it's really useful because it reminds them of the old days, keeps them warm, and still cooks food." Science Concept Explained: Convection \& Conduction

Nidia also made a reference to her direct experience with Italian skirts and an Italian invention, batteries (Picture 4). Nidia shared her knowledge of the weather in Italy to provide relevant background information. Then she introduced the skirt as clothing that prevents heat transfer. She wrote, "If the skirt is a lighter color, it will not absorb heat, but if the skirt is darker, it will absorb heat." Nidia also explored batteries, an important Italian invention. She mentioned that her cultural connection to Italy linked her to the invention. She said it is "cool" to realize batteries were invented in her home country because everyone uses batteries. 


\section{Picture 4}

\section{Nidia's Italian Skirts and Batteries}

Clothing that keeps us warm or cool

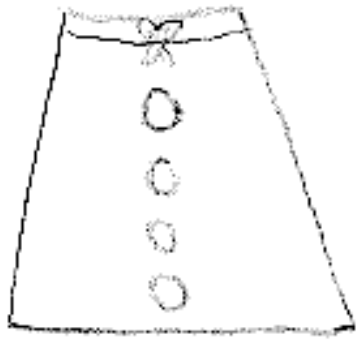

"In Italy, girls wear skirts. I chose a skirt because I am a girl and skirts are popular for girls in Italy..."

Science Concept Explained: None
Famous inventions from my home country/ town or elsewhere

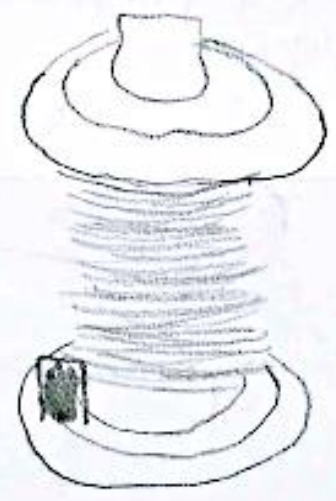

"We chose the battery because we use batteries every day, and we are from Italy.

So, we thought it would be cool and it caught our attention."

Science Concept Explained: None

Naomi also drew on her family members' experiences with a cultural object. She introduced a parka as insulating clothing from Canada and described her grandfather wearing it to prevent heat transfer (Picture 5). She also demonstrated her knowledge of Canada's wet and cold weather to provide background information about parkas and their materials. She explained that this clothing reminded her mother of childhood in Canada: "When we wear parkas in the winter, it reminds my mom of the winters she spent there." 


\section{Picture 5.}

\section{Drawing of Naomi's Grandfather's Parka}

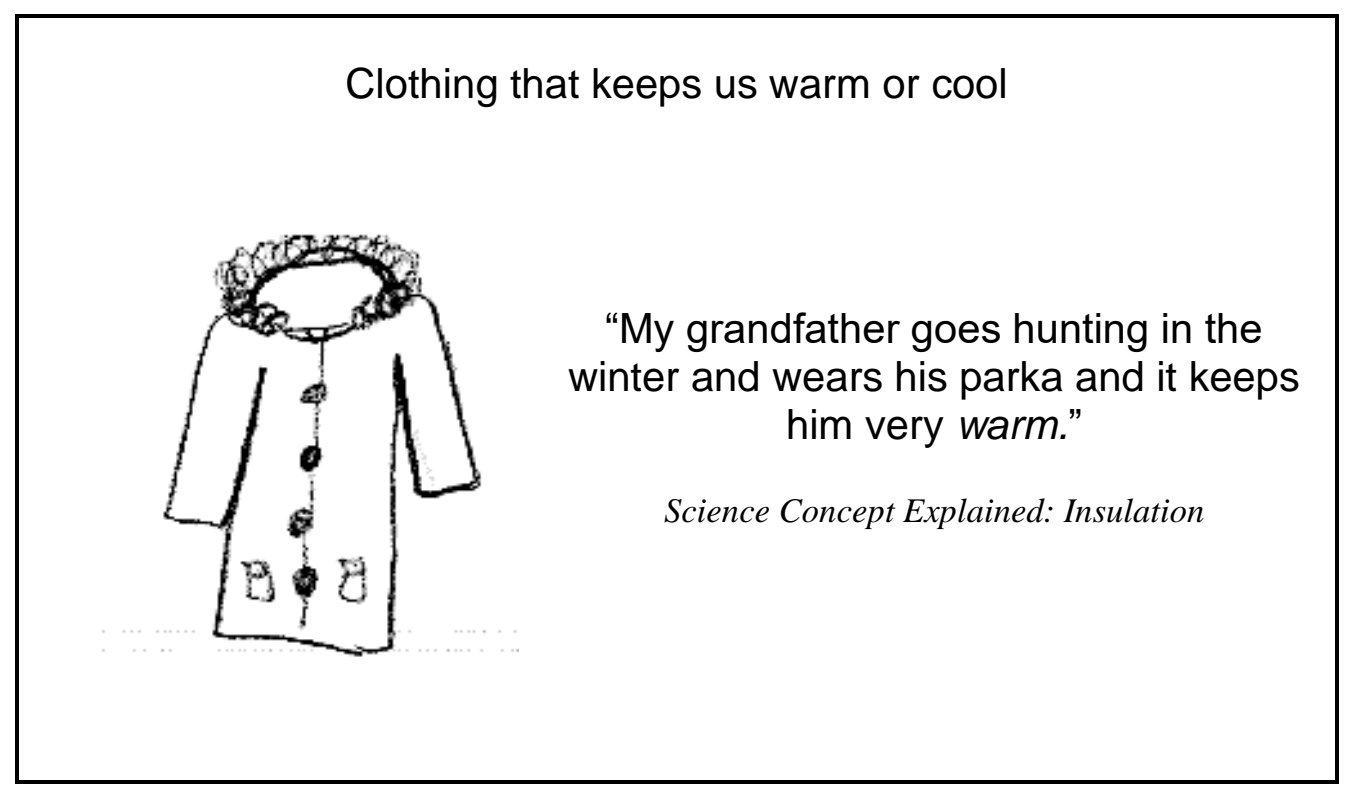

Every bicultural student drew on either direct or indirect cultural knowledge. They all described how their families were connected to and took pride in an invention.

\section{Bicultural Students' Experience of the HomeFun Activities}

Each student reported that one or more family members were deeply involved in their HomeFun activities. They all reported a positive, enjoyable experience connecting with their family, country, and home culture. The HomeFun activities brought family together and made learning more meaningful to the bicultural students and their family members. The activities provided an opportunity for families to share cultural knowledge, experiences, and values. For many, the family discussions brought back memories of and pride in their heritage.

\section{Mandy: "That was cool to learn [that] it was a big Italian thing."}

Mandy said that being able to talk about the Italian brick oven with her grandmother was useful, fun, and "cool."

It was pretty cool, being able to talk about the brick oven, because I have a little bit of experience. So, I just asked her [grandmother] a lot of questions about it...She talked about how it works and how she makes the pizza or the bread on it, and it was really good.

In addition to learning about the functioning of an Italian oven, she also learned family history. Even though Mandy had experience using the brick oven in her grandmother's backyard, she did not know about the family history behind it. After learning more, she became excited about the culture and tradition of the family oven. She reported that she was proud to know such a great invention was "a big Italian thing." 


\section{Sam: "It actually connected you [with family]."}

Like Mandy, Sam had fun learning about her country's invention, the Moroccan clay oven, from her family members. She enjoyed her mother's amusing stories about cooking with the oven back in Morocco. Her mother told her that, because the oven is huge, she had to almost walk inside the oven to place the food. She said listening to her mother's experiences using the oven reminded her about the hot weather back in Morocco, brought back memories of her life there, and made her feel connected to her country and family. She stated, "I felt it [HomeFun activity] actually connected you [with family]...it was bringing back memories, just thinking, just like pictures."

Sam was also fascinated to learn about the differences between American and Moroccan cooking culture. She learned how cooking has a different meaning in Morocco. She explained how most Moroccan family members participate in cooking such that it becomes easier, more collaborative, and interactive than it is in the United States.

I learned a lot of things. It was just that even if it was back then, it [cooking] was easier to do because there were a lot of people working together. So, I feel you can communicate over it. You have a conversation instead of just putting it in the oven and putting a timer on it.

\section{Mia: "It was fun because usually I don't really talk about this stuff with my mom."}

Mia also built a strong connection to her family and culture while engaging in the HomeFun activities. She learned about the Guatemalan firewood griddle from her mother and grandmother. She enjoyed this activity not only because of the meaningful interaction with her family, but also because she was able to learn about her mother's childhood. Mia enjoyed hearing her mother's stories and she realized how different their childhood experiences were.

It was fun because usually I don't really talk about this stuff with my mom. So, her and my grandma [were] sitting down with me, they were just talking that wasn't about the product. But my mom mentioned a lot of childhood memories, which I didn't know about.

Mia explained that her mother had to do a lot of chores and manual work such as making skirts to help her grandmother. Mia found these stories new and valuable. She said that the HomeFun activity was especially enjoyable because, through learning about her mother's childhood experiences, she was able to understand, learn, and connect with her mother more. 


\section{Naomi: "When we do it with our family, I think it made more sense to me."}

Naomi reported a similar experience. She had fun discussing her home country with her parents because it brought back memories of family visits to her grandfather and cousins in Canada. She said her parents were very involved in the activities. She enjoyed talking with her mother about her grandfather's hunting. Her mother described experiences hunting and the weather in Canada. She mentioned that she had seen her grandfather wearing a parka to go hunting. She found the HomeFun activities enjoyable because they connected to her mother's experiences.

\section{Nidia: "It sounds cool."}

Nidia also described how it was fun to connect with her father and learn about Italian inventions together. She said her father was very involved in the activity. They searched online together to collect information about Italy and its inventions. Nidia said she was astonished to discover many great inventions from Italy. Nidia and her father chose the battery as the Italian invention to explore because it is omnipresent in daily life. As they researched the history of batteries, they were surprised to find out how batteries evolved.

When I was doing research and I saw it at first, I didn't know what it was. It looked weird. So, I looked into it more and I figured out that it was [how] the first battery looked like! I was just confused how that can turn into what it is today... It is so cool.

She emphasized that it was "so cool" to learn about this invention.

\section{Cynthia: "You got to write your own personal life and what it's like at home."}

Like Nidia, Cynthia enjoyed learning about cultural objects related to her life. "I liked it because you got to write your own personal life and what it's like at home, what you're like, and where you're from." She said that talking to her parents about Greece brought back memories of her grandmother's Greek slippers and those memories made her feel connected to her country. She also mentioned that this was a good opportunity for her to learn about family traditions like knitting. Cynthia reported that the HomeFun activities provided a meaningful opportunity for her family to share memories, values, traditions, and experiences, and this brought them closer.

Taken together, then, these cases show that the culturally relevant HomeFun activities: 1) helped the bicultural students feel closer to their culture and family; 2) helped the bicultural students recognize science in their own culture and in daily life; and 3) encouraged the bicultural students' parents to be involved in their children's schoolwork. Each student reported a valuable experience connecting with family members, and they appreciated learning about the family's experiences, culture, and knowledge. It was an opportunity for the students to think and appreciate culture, traditions, and values which were often ignored during their everyday lives. At the same time as these family and cultural experiences were valuable in and of themselves, they also connected to science concepts (i.e., convection, conduction, insulation, heat transfer) being taught in class. 


\section{Science Learning through HomeFun Activities}

The HomeFun activities helped the bicultural students to understand the heat transfer concepts learned in school. All students reported that HomeFun activities helped them learn science by 1) facilitating comprehension of heat transfer, 2) making science learning engaging, and 3) bridging home and school learning.

Most bicultural students reported greater understanding of science concepts after completing the HomeFun activities. For example, Sam said that learning about the Moroccan clay oven helped her to understand thermal energy. Even though she had known the Moroccan oven all her life, she did not recognize the heat transfer principles exemplified in the heating device.

While looking at the oven, I didn't really think about science. It's an oven. And then while doing this, I really thought about it. I'm like, "That makes sense now!" How the potential [and] thermal [energy work]... It just made more sense!

Similarly, Mandy, Mia, and Naomi reported that the HomeFun activities made science concepts easier to comprehend. The in-depth conversations with family and the cultural examples in the HomeFun activities helped them make sense of heat transfer. Nidia talked about how HomeFun activities increased her understanding of heat transfer concepts by pushing her to think beyond given information:

Because, when you learn about it in books, they are not going to have these [cultural objects] as examples. So [when you do the HomeFun activities] you have to use your brain and actually think about it and see how they come together. Not just look at the book and get the answer from it.

In addition to increased comprehension, all bicultural students said that the HomeFun activities made science learning more fun, engaging, and personal. Mia and Mandy found this activity enjoyable and "cool" because it related to home, culture, and identity. Mia said that learning from home culture made science less "sciency" and more friendly. Mandy stated that learning science from her home culture was "something special" and personalized. Sam added that learning from cultural experiences and traditional knowledge was a meaningful way to study science because "It had to do with [my] culture."

Students explained how the HomeFun activities became a bridge to connect school and home. For example, Naomi said that the HomeFun activities were helpful because of the connections to what she was learning at school. Her understanding of radiation developed through engaging in the lunchbox invention process and the HomeFun activities:

I think that the HomeFun activities connect to the project because it is talking about how to keep you warm using conduction, radiation, and convection and use all those. So, the HomeFun activities help us [to] know more about what they taught us in the classroom [and] how everything works. 
She reported that she and her family "had to figure out where the radiation was coming from in the HomeFun activities and how the radiation worked in the lunchbox." She expressed excitement when she figured out the connection between the two activities: "It was good...like who came up with it?"

Naomi's report on her lunch box demonstrated her understanding of heat transfer and its connection to the HomeFun activity. For example, after explaining the process of heat transfer in her lunchbox, she made a connection to a real-life example of how humans prevent heat transfer:

The first type of heat transfer is radiation, which is emission of energy as electromagnetic waves or as moving subatomic particles, especially highenergy particles that cause ionization. The radiation is most seen when occurring with the tin foil in the project because the movement from the heat going into, and the box hitting the tin foil on top and white paper...Humans try to stop heat transfer from coming to them in the summer, so they would most likely put a white t-shirt on or a lighter color t-shirt.

Her accurate account of light clothing colors here reveals her new understanding.

Cynthia also made a connection between the lunchbox invention and the HomeFun activities. She started to like science: "I couldn't wait because I like connecting my home culture to school!" She figured out that the school and home activities both focused on the fundamentals of heat transfer. She thought about how she reduced heat transfer in her lunch box and then applied these concepts to the HomeFun activity. She used school knowledge to understand heat transfer in her cultural object. Her report shows this:

In my cooler, I see conduction... because when we close the box, there is more heat and cold trying to come in and out of the cooler. For example, when you're in your house and the heat is on, when you open a window the cold and heat fight to see where they are going to go.

However, despite students' positive reports about connecting science with home, not every student's HomeFun activity applied the scientific concepts. Some students struggled to make a connection, while others demonstrated clear understanding of the science behind the cultural object. Mia, Sam, Cynthia, and Mandy chose traditional heating devices from their countries, but their application of heat transfer concepts to the heating devices varied from extensive to minimal. On the other hand, Nidia and Naomi's HomeFun activities did not use any heat transfer concepts.

Sam and Mia successfully used their knowledge of heating devices to understand scientific concepts learned in class. Their explanations demonstrated their understanding of the fundamentals of heat transfer. Sam included both convection and conduction as types of heat transfer used in Moroccan clay ovens. Moroccan clay ovens involve "conduction because the fire is below the object (food placing rack). Convection because the air circulating is warmer and helps deliver heat to the object." Sam also explained how this process of heating involves both thermal and potential energy. Mia, who chose a similar heating device, provided a 
different explanation. She indicated that conduction is the major heat transfer mechanism used in fire griddles. "It does successfully deliver heat to the object through conduction. This is because when the cooking pot is touching the wood. Then, the heat will transfer directly." Their drawings demonstrated why and how heat transfer differs between Moroccan ovens and Guatemalan firewood griddles (Picture 6).

\section{Picture 6}

\section{Drawings of Sam's Moroccan Clay Oven and Mia's Firewood Griddles}

\begin{tabular}{|c|c|}
\hline $\begin{array}{l}\text { How we heat or cook things in my home } \\
\text { country/town }\end{array}$ & $\begin{array}{l}\text { How we heat or cook things in my home } \\
\text { country/town }\end{array}$ \\
\hline$\uparrow_{\text {fire }}$ Frack above & $\cdot$ \\
\hline $\begin{array}{l}\text { "Conduction because the fire is below the } \\
\text { object (food placing rack). Convection } \\
\text { because the air circulating is warmer and } \\
\text { helps deliver heat to the object" -Sam } \\
\text { Science concept explained: Conduction and } \\
\text { Convection }\end{array}$ & $\begin{array}{c}\text { "It does successfully deliver heat to the } \\
\text { object through conduction. This is } \\
\text { because when the cooking pot is touching } \\
\text { the wood. Then, the heat will transfer } \\
\text { directly."- Mia } \\
\text { Science concept explained: Conduction }\end{array}$ \\
\hline
\end{tabular}

Sam's Moroccan clay oven has a rack above the fire, and conduction occurs when the high temperature rack transfers heat to food. In addition, because the Moroccan oven is shielded with clay, the heat inside the oven continues to warm up the food. Sam's description showed her understanding of the oven and the science. Mia's explanation of the firewood griddle also showed her understanding of heat transfer concepts. She showed how the firewood griddle heats up the pot with conduction from the fire. She did not include convection as a type of heat transfer because, unlike the Moroccan clay oven, the firewood griddle does not have a shield that keeps heated air around the food. Sam's and Mia's explanations accurately described the heat transfer used in their devices. 
Even though Mandy and Cynthia chose similar heating devices, their connection to science was weak. Mandy wrote that the Italian brick oven involves hot air inside. However, she was not able to make a connection to any of the heat transfer concepts. She wrote that convection may be involved in the process, but she did not provide an explanation or reason. Similarly, Cynthia's wood stove explanation did not include any scientific explanation. She wrote, "a wood stove works by putting wood into the stove and burns. That's how it creates heat." She understands that heat is generated in the stove, but she failed to explain how the heat from the wood stove is transferred to cook food. Similarly, Nidia did not make a connection between her cultural object and heat transfer. Her illustration and explanations only included her experiences and cultural knowledge, not any of the scientific concepts behind the object.

Each student used the culture drawn on in HomeFun activities as a resource that provided some connection to subject matter, as well as motivation to engage in learning science. Some of them made systematic use of scientific concepts while reflecting on their home cultural inventions. These cases show the potential positive effects of using home culture resources to teach science.

\section{Discussion and Implications}

In addition to their increased understanding of heat transfer, the bicultural students enjoyed feeling connected to and learning about their cultures, family values, and personal experiences. They appreciated learning from their family members' experiences. The HomeFun activities provided an opportunity for the students to remember and appreciate cultural traditions that were often ignored in their daily lives. This section summarizes our findings about culture and knowledge transfer.

\section{Transferring Cultural Knowledge}

Knowledge transfer is an on-going process that students engage in while learning (Engle, 2006; Salomon \& Perkins, 1989). We argue that culture can facilitate the process of knowledge transfer from one context to another. According to Engle et al. (2012), a sense of authorship helps motivate students, making learning content more personal, and it can facilitate knowledge transfer. In our case, each student's cultural knowledge provided a sense of ownership because the knowledge was personally connected to them. The HomeFun activities provided an opportunity for students to explore their funds of knowledge (Moll et al., 1992) and facilitated family involvement in school science. These bicultural students were able to learn from family about their culture and their parents' childhood experiences. They reported that HomeFun activities brought the family together and evoked pleasant memories. Learning about heat transfer concepts through culture was meaningful to them and their family members. In addition, they reported that these activities made science "cool" and "fun" because they connected their culture with school. For example, Sam expressed her excitement that "I did [enjoy it] especially because it had to do with my culture and tradition." Cynthia said, "I couldn't wait 'cause I like connecting my home culture to school!" Linking school with home culture made science more comfortable and enjoyable. 
Science was less "sciency" and became more friendly. The HomeFun activities became a bridge to connect school to home knowledge and helped create an exciting science learning environment at home.

\section{Knowledge Transfer: A Diverse and Bi-directional Process}

Perkins and Salomon (2012) argue that three "bridges," detect-electconnect, are necessary during knowledge transfer. Detect is when a learner identifies the object, situation, or phenomenon. Elect is when a learner explores the link between the knowledge and the objects/situations/phenomena. Connect is the process in which the learner successfully expands the knowledge and applies it to the new setting.

Our six bicultural students engaged in detect-elect-connect while doing HomeFun activities. They detected the heat transfer concepts when they recognized their cultural objects as heating devices. Then they explored the object to elect the heat transfer principles exemplified by the objects. Lastly, they connected the heat transfer principles learned in school to the cultural object. Some, like Cynthia, Mandy, and Sam, went one step further and connected their lunchbox invention experience with the cultural object as well.

But this connect process did not come naturally for everyone in the study. There was substantial variation among the bicultural students in making connections between the two contexts. The connections came easily for Sam and Naomi. During the interview, Sam reported that making connections was an easy and natural process, just as Perkins and Salomon (2012) describe. This did not happen for everyone, however. Sam and Mia made connections easily and smoothly. Nidia did not make any connection at all. Mandy, Cynthia, and Naomi made some (Table 4).

\section{Table 4}

\section{Differential Outcomes among Students}

\begin{tabular}{|c|c|c|}
\hline Strong Connection & Weak Connection & No Connection \\
\hline Sam and Mia & $\begin{array}{c}\text { Mandy, Cynthia, and } \\
\text { Naomi }\end{array}$ & Nidia \\
\hline
\end{tabular}

This variation in knowledge transfer resulted from three factors: 1) stronger and weaker content knowledge, 2) varied timing across individuals, and 3) complexities in the knowledge transfer process. First, it is clear that acquiring deep knowledge of content is essential to knowledge transfer (Bransford et al., 1999; Chi \& VanLehn, 2012; Engle et al., 2012). As Engle et al. (2012) argue, "the most fundamental prerequisite for transfer is that the particular content to be transferred has been learned in a sufficiently deep, strong, and lasting way" (p.216). The students who did not grasp heat transfer could not transfer knowledge from school to their cultural contexts easily. Once they built a strong understanding of heat transfer concepts, they were able to apply it to HomeFun activities. 
Second, students required more or less input in order to accomplish knowledge transfer. For some students, like Sam and Mia, knowledge gained from school was transferred to the cultural context effortlessly, from the beginning. But students like Mandy, Cynthia, and Naomi needed multiple conversations before making a connection between the two contexts. This reflects individual differences in the amount of input necessary to engage in knowledge transfer. Some students may still have been developing their science knowledge while engaging in the HomeFun activities and were thus not ready to transfer the concepts. For some students the HomeFun activities acted as an opportunity to practice heat transfer concepts; whereas, for others, HomeFun activities were an opportunity to apply already understood concepts. As Nidia said about the HomeFun activities: "I mean, it wasn't easy. I had to actually do work and research for it, but it got easier over time."

Third, our findings illustrate how the knowledge transfer process is not simple and one-way. Instead, knowledge transfer is an iterative bi-directional process. First, the heat transfer knowledge gained from school was used to understand phenomena in the HomeFun activities. Then the knowledge gained from the HomeFun activities became a resource to solidify the knowledge gained in school. This was a positive feedback loop. For example, despite the variation in comprehension among the bicultural students, all of them said that they used the heat transfer knowledge to complete the HomeFun activities and also that the HomeFun activities contributed to their understanding of heat transfer. As students moved back and forth between the two contexts, their comprehension solidified. In the successful cases, "the degree of intercontextuality get so strong that a larger encompassing context is formed that seamlessly incorporates learning and transfer contexts" (Engle et al., 2012, p.218). This was evident when some bicultural students voluntarily transferred knowledge from the HomeFun activity to the lunch box invention. For example, when Naomi figured out the connection between the lunchbox invention and her HomeFun activities, she was surprised and excited: "It was good... [I was] like, "Who came up with it?"

This study has several implications. First, students need to have various opportunities to engage science in diverse contexts. Since individuals need different amounts of input, it is important to provide various contexts and diverse practice to give everybody a chance to engage in knowledge transfer. Second, culture is a useful resource to help students connect their knowledge across school and home. Connecting to students' home cultures and their funds of knowledge is both a motivational resource for learning science (Maulucci et al., 2014) and an effective academic resource which makes science learning more meaningful. As science becomes friendly and enjoyable, it lowers anxiety and encourages students to engage in scientific thinking in and outside of the classroom (Barton \& Tan, 2009; Gay, 2002; Kaya \& Yıldırım, 2014; Sağır, 2012). By incorporating culturally relevant activities like HomeFun, we can build pride in home cultures and students can learn science more effectively. 


\section{References}

Adams, A., \& Laughter, J. (2012). Making space for space traders. Multicultural Learning and Teaching, 7(2). https://doi.org/10.1515/2161-2412.1121

Barnett, S., \& Ceci, S. (2002). When and where do we apply what we learn? A taxonomy for far transfer. Psychological Bulletin 128, 612-37. https://doi.org/10.1037/0033-2909.128.4.612

Barton, A. C. (2002). Urban science education studies: A commitment to equity, social justice and a sense of place. Studies in Science Education, 38(1),138. https://doi.org/10.1080/03057260208560186

Barton, A. C., \& Tan, E. (2009). Funds of knowledge and discourses and hybrid space. Journal of Research in Science Teaching, 46(1), 50-73. https://doi.org/10.1002/tea.20269

Bassey, M. O. (2016). Culturally responsive teaching: Implications for educational justice. Education Sciences, 35. https://doi.org/10.3390/educsci6040035

Basu, S. J., \& Barton, A. C. (2007). Developing a sustained interest in science among urban minority youth. Journal of Research in Science Teaching, 44(3), 466-489. https://doi.org/10.1002/tea.20143

Benet-Martínez V., \& Haritatos J. (2005). Bicultural identity integration (BII): Components and psychosocial antecedents. Journal of Personality. 73, 1015-1050. https://doi.org/10.1111/j.1467-6494.2005.00337.x

Bereiter, C., \& Scardamalia, M. (1987). The psychology of written composition. Lawrence Erlbaum Associates.

Boutte, G., Kelly-Jackson, C., \& Johnson, G. L. (2010). Culturally relevant teaching in science classrooms: Addressing academic achievement, cultural competence, and critical consciousness. International Journal of Multicultural Education, 12(2). http://dx.doi.org/10.18251/ijme.v12i2.343

Bransford, J., Bransford, J. D., Brown, A. L., \& Cocking, R. R. (1999). How people learn: Brain, mind, experience, and school. National Academies Press.

Brickhouse, N. W., Lowery, P., \& Schultz, K. (2000). What kind of a girl does science? The construction of school science identities. Journal of Research in Science Teaching, 37(5), 441-458. https://doi.org/10.1002/(SICI)10982736(200005)37:5<441::AID-TEA4>3.0.CO;2-3

Brown, B. A., Boda, P., Lemmi, C., \& Monroe, X. (2019). Moving culturally relevant pedagogy from theory to practice: Exploring teachers' application of culturally relevant education in science and mathematics. Urban Education, 54(6), 775-803. https://doi.org/10.1177/0042085918794802

Business Roundtable Group. (2005). Tapping America's potential: The education for innovation initiative. Retrieved from www.businessroundtable.org. 
Chi, M. T., \& VanLehn, K. A. (2012). Seeing deep structure from the interactions of surface features. Educational Psychologist, 47(3), 177-188. Dallavis, C. (2014). Culturally responsive caring and expectations for academic achievement in a Catholic school. Journal of Catholic Education, 17(2), 154-171. https://doi.org/10.1080/00461520.2012.695709

Djonko-Moore, C. M., Leonard, J., Holifield, Q., Bailey, E. B., \& Almughyirah, S. M. (2018). Using culturally relevant experiential education to enhance urban children's knowledge and engagement in science. Journal of Experiential Education, 41(2), 137-153. https://doi.org/10.1177/1053825917742164

Engle, R. A. (2006). Framing interactions to foster generative learning: A situative explanation of transfer in a community of learners classroom. The Journal of the Learning Sciences, 15(4), 451-498. https://doi.org/ 10.1207/s15327809jls1504_2

Engle, R. A., Lam, D. P., Meyer, X. S., \& Nix, S. E. (2012). How does expansive framing promote transfer? Several proposed explanations and a research agenda for investigating them. Educational Psychologist, 47(3), 215-231. https://doi.org/10.1080/00461520.2012.695678

Gay, G. (2002). Preparing for culturally responsive teaching. Journal of teacher education, 53(2), 106-116. https://doi.org/10.1177/0022487102053002003

González, N., Moll, L. C., \& Amanti, C. (Eds.). (2006). Funds of knowledge: Theorizing practices in households, communities, and classrooms. Routledge.

Johnson, C. C. (2011). The road to culturally relevant science: Exploring how teachers navigate change in pedagogy. Journal of Research in Science Teaching, 48(2), 170-198. https://doi.org/10.1002/tea.20405

Kaya, E., \& Yildirim, A. (2014). Science anxiety among failing students. Elementary Education Online, 13(2). http://ilkogretim-online.org// $? \mathrm{mno}=123125$

Kim, D., Cho, E., Couch, S., \& Barnett, M. (2019). Culturally relevant science: Incorporating visualizations and home culture in an invention-oriented middle school science curriculum. Technology \& Innovation, 20(3), 251266. https://doi.org/10.21300/20.3.2019.251

Kim, S. L., \& Kim, D. (2021). English learners' science-literacy practice through xplicit writing instruction in invention-based learning. International Journal of Educational Research Open, 2, 100029. https://doi.org/ 10.1016/j.jjedro.2020.100029

Ladson-Billings, G. (1994). The dreamkeepers: Successful teachers of African merican children. Jossey-Bass.

Ladson-Billings, G. (1995). But that's just good teaching! The case for culturally relevant pedagogy. Theory into practice, 34(3), 159-165. https://doi.org/10.1080/00405849509543675 
Ladson-Billings, G. (2009). The dreamkeepers: Successful teachers of African American children. John Wiley \& Sons.

Ladson-Billings, G. (2014). Culturally relevant pedagogy 2.0: aka the remix. Harvard Educational Review, 84(1), 74-84. https://doi.org/10.17763/haer.84.1.p2rj131485484751

Laughter, J. C., \& Adams, A. D. (2012). Culturally relevant science teaching in middle school. Urban Education, 47(6), 1106-1134. https://doi.org/10.1177/0042085912454443

Lee, O. (2002). Science inquiry for elementary students from diverse backgrounds. Review of Research in Education, 26, 23-69. https://doi.org/10.3102/0091732X026001023

Lee, O. (2005). Science education with English language learners: Synthesis and research agenda. Review of Educational Research, 75(4), 491-530. https://doi.org/10.3102/00346543075004491

Lee, O., Deaktor, R. A., Hart, J. E., Cuevas, P., \& Enders, C. (2005). An instructional intervention's impact on the science and literacy achievement of culturally and linguistically diverse elementary students. Journal of Research in Science Teaching, 42(8), 857-887. https://doi.org/10.1002/tea.20071

Maulucci, M. S. R., Brown, B. A., Grey, S. T., \& Sullivan, S. (2014). Urban middle school students' reflections on authentic science inquiry. Journal of Research in Science Teaching, 51(9), 1119-1149. https://doi.org/10.1002/tea.21167

McLaughlin, D. S., \& Barton, A. C. (2013). Preservice teachers' uptake and understanding of funds of knowledge in elementary science. Journal of Science Teacher Education, 24(1), 13-36. https://doi.org/10.1007/s10972012-9284-1

Mensah, F.M. (2013). Theoretically and practically speaking, what is needed in diversity and equity in science teaching and learning? Theory into Practice, 52(1), 66-72. https://doi.org/10.1080/00405841.2013.743781

Merriam, S. B., \& Tisdell, E. J. (2015). Qualitative research: A guide to design and implementation. John Wiley \& Sons.

Milner, H. R., IV. (2017). Where's the race in culturally relevant pedagogy? Teachers College Record, 119(1), 1-32.

Moll, L. C., Amanti, C., Neff, D., \& Gonzalez, N. (1992). Funds of knowledge for teaching: Using a qualitative approach to connect homes and classrooms. Theory into Practice, 31(2), 132-141. https://doi.org/ 10.1080/00405849209543534

Morrison, K. A., Robbins, H. H., \& Rose, D. G. (2008). Operationalizing culturally relevant pedagogy: A synthesis of classroom-based research. Equity \& 
Excellence in Education, 41(4), 433-452. https://doi.org/ $10.1080 / 10665680802400006$

National Center for Education Statistics (2005). Trends in international mathematics and science study. Trends in International Mathematics and Science Study. Retrieved from http://nces.ed.gov/pubs2005/2005005.pdf.

National Center for Education Statistics. (2016). Fast facts: English language learners. Retrieved from https://nces.ed.gov/fastfacts/display.asp?id=96.

Ochs, E., \& Taylor, C. (1992). Family narrative as political activity. Discourse \& Society, 3(3), 301-340. https://doi.org/10.1177/0957926592003003003

Pak, C. S. (2018). Linking service-learning with sense of belonging: A culturally relevant pedagogy for heritage students of Spanish. Journal of Hispanic Higher Education, 17(1), 76-95. https://doi.org/10.1177/ 1538192716630028

Perkins, D. N., \& Salomon, G. (2012). Knowledge to go: A motivational and dispositional view of transfer. Educational Psychologist, 47(3), 248-258. https://doi.org/10.1080/00461520.2012.693354

Razfar, A., \& Nasir, A. (2019). Repositioning English learners' funds of knowledge for scientific practices. Theory into Practice, 58(3), 226-235. https://doi.org/10.1080/00405841.2019.1599231

Saad, C. S., Damian, R. I., Benet-Martínez, V., Moons, W. G., \& Robins, R. W. (2012). Multiculturalism and creativity: Effects of cultural context, bicultural identity, and ideational fluency. Social Psychological and Personality Science, 4(3), 369-375. https://doi.org/10.1177/1948550612456560

Sağır, Ş. U. (2012). The primary school students' attitude and anxiety towards science. Journal of Baltic Science Education, 11(2), 127-140.

Salomon, G., \& Perkins, D. N. (1989). Rocky roads to transfer: Rethinking mechanism of a neglected phenomenon. Educational Psychologist, 24(2), 113-142. https://doi.org/10.1207/s15326985ep2402_1

Scardamalia, M., \& Bereiter, C (1987). Knowledge telling and knowledge transforming in written composition. In S. Rosenberg (Ed.), Advances in Applied Psycholinguistics, Vol. 2: Reading, Writing and Language Learning (p. 142-175). Cambridge University Press.

Schwartz S.J., Zamboanga B.L. (2008). Testing Berry's model of acculturation: A confirmatory latent class approach. Cultural Diversity and Ethnic Minority Psychology, 14, 275-285. https://doi.org/10.1037/a0012818

Solomon, J. (2003). Home-school learning of science: The culture of homes, and pupils' difficult border crossing. Journal of Research in Science Teaching, 40(2), 219-233.https://doi.org/10.1002/tea.10073

Tan, E., \& Barton, A. C. (2008). Unpacking science for all through the lens of identities-in-practice: The stories of Amelia and Ginny. Cultural Studies of 
Science Education, 3(1), 43-71. https://doi.org/10.1007/s11422-007-90767

Upadhyay, B. (2009). Teaching science for empowerment in an urban classroom: A case study of a Hmong teacher. Equity \& Excellence in Education, 42(2), 217-232. https://doi.org/10.1080/10665680902779366

Vygotsky, L. S. (1978). Mind in society: The development of higher psychological processes. Harvard University Press. https://doi.org/10.2307/j.ctvjf9vz4

Warren, B., \& Rosebery, A. S. (2008). Using everyday experience to teach science. In A. S. Rosebery \& B. Warren (Eds.), Teaching Science to English Language Learners (pp. 39-50). National Science Teachers Association.

West, M. T., \& Maffini, C. S. (2019). "What are you?" Conceptualizing the complexities of bicultural and biracial college student experiences. Journal of College Counseling, 22(2), 164-178. https://doi.org/10.1002/jocc.12128

Zimmerman, H. T. (2012). Participating in science at home: Recognition work and learning in biology. Journal of Research in Science Teaching, 49(5), 597630. https://doi.org/10.1002/tea.21014

\section{Author Contact}

Deoksoon Kim, deoksoon.kim@bc.edu

Professor, Teaching, Curriculum, and Society

Lynch School of Education \& Human Development

Boston College, Campion 127, 140 Commonwealth Avenue

Chestnut Hill, MA 02467

So Lim Kim, kimagv@bc.edu

Ph.D. Candidate, Teaching, Curriculum, and Society

Lynch School of Education \& Human Development

Boston College, Campion 211, 140 Commonwealth Avenue

Chestnut Hill, MA 02467

Mike Barnett, barnett@bc.edu

Professor, Teaching, Curriculum, and Society

Lynch School of Education \& Human Development

Boston College, Campion 123, 140 Commonwealth Avenue

Chestnut Hill, MA 02467 